\title{
CURRENT TRENDS IN TISSUE-AFFECTING HELMINTHS
}

\author{
GOTTSTEIN B.* \& PIARROUX R.**
}

\section{Summary:}

Some helminths have by their evolution learnt to systemically invade a host organism, and to select specific organs or host cell types as predilection site to reside, maturate or even proliferate. These parasites needed to develop complex and unique strategies to escape host immune reactions. The present work sheds some light into the strategy developed by three different helminths (Echinococcus multilocularis, Trichinella spiralis and Toxocara canis) to survive in the host organ or host cell, respectively. The crucial role of periparasitic host reactions that may help the host to control the parasite, but which may also be responsible for immunopathological events harmful to the host himself, are elucidated as well. Finally, for these three parasites selected, the murine host appears an acceptable model for carrying out experimental studies, as for these parasites, rodents as well as humans become infected in the parasites natural life cycle. Therefore, conclusions drawn from murine experiments may provide much more reliable data in view of their relevance for the human infection, a fact that frequently lacks when using mice as experimental model for other helminths.

KEY WORDS : echinococcosis, trichinellosis, toxocariasis, immunity, immunopathology, proteases.

T The list of helminthic parasites infecting humans is long and rich in species diversity. Although the most prominent fundamental niche parasitized by these helminths is the gastro-intestinal (GI) tract, a series of helminths have by their evolution learnt to systemically invade the actual host organism, and to select specific organs or host cell types as predilection site to reside, maturate or even proliferate, until life-cycle continues in another host. Some of these helminths enter the host via the GI, but subsequently they will continue their pathway by penetrating first into the intestinal epithelium and lamina propria, after which they will be transported via blood or lymph to the anticipated predilection site. Echinococcus multilocularis, after leaving the intestinal tissue, will reach the next anatomical capillary system represented by the liver, thus metacestode deve-

* Institute of Parasitology, Vetsuisse Faculty, University of Bern, Bern, Switzerland.

** Parasitology Department, SERF Team (Équipe Santé Environnement Rural Franche-Comté), Faculty of Medicine, University of FrancheComté, Besançon, France.

Correspondence: Bruno Gottstein.

E-mail: bruno.gottstein@ipa.unibe.ch lopment will primarily occur in the liver parenchyma. Some other larval stages of cestodes (not Echinococcus), and the newborn larval stage of the nematode Trichinella spiralis, will find their home in striated skeletal muscle tissue. Third stage larvae (Brunaska et al., 1995) of Toxocara canis migrate to muscles, brain and visceral tissues in human and other intermediate (paratenic) hosts. While Trichinella larvae have become successful as intracellular parasites, T. canis and E. multilocularis principally remain at an extracellular stage of parasitism. All three parasite needed to develop complex and unique strategies to escape host immune reactions. Efficiency and efficacy of those strategies are proven by the fact that all three parasites are able to persist in their hosts for many years or more. They will survive in the organ or the host cell without actually causing death. Therefore, these parasites are considered as very successful, in that disease is an aberrant finding occurring primarily only in humans, which do actually not participate in the completion of the natural life cycle. In the following chapter, we will shed some light into the parasite strategy developed to survive in the host organ or cell, respectively, and into the periparasitic host reaction that may help the host to control the parasite, but which may also be responsible for immunopathological events harmful to the host himself. Finally, for these three parasites selected, the murine host appears an acceptable model for carrying out experimental studies, as for these parasites, rodents as well as humans become infected in the parasites natural life cycle. Therefore, conclusions drawn from murine experiments may provide much more reliable data in view of their relevance for the human infection, a fact that frequently lacks when using mice as experimental model for other helminths.

\section{BIOLOGICAL FEATURES OF ECHINOCOCCUS MULTILOCULARIS METACESTODES}

The metacestode that causes alveolar echinococcosis (AE) consists of a cluster of fluid-filled vesicles, which are structured into a cellular and an acellular compartment. The outer acellular surface of 
the metacestode is formed by the laminated layer, a carbohydrate-rich structure synthesized by the parasite. The laminated layer plays a crucial role in the survival strategy of the parasite by modulating immunological and physiological reactions on part of the host The actual larval tissue is formed by the germinal layer, the distal part of which consists of the tegument that is directly associated with the inner surface of the laminated layer. The tegument is characterized by microvilli-like extensions termed microtriches, which protrude well into the matrix of the laminated layer and increase the resorbing surface of the parasite. In addition, the germinal layer contains highly differentiated cell types including connective tissue, muscle cells, and glycogen storage cells, as well as many undifferentiated cells. In E. multilocularis infection, metacestode development is closely intermingled with host (liver) connective tissue, the metacestode represents a multi-vesicular structure that reproduces asexually, by exogenous formation and budding of daughter vesicles, which resembles progressive tumour-like growth (Fig. 1). This leads to the formation of a large and heterogenuous parasitic mass, which exhibits mostly peripheral actively proliferating sites, and in many cases, centrally located necrotic tissue. Metastases formation may occur in other organs due to release of germinal layer cells into the blood or lymph system. E. multilocularis protoscoleces development in humans has been described only rarely.

\section{MURINE IMMUNE RESPONSE IN E. MULTILOCULARIS INFECTION}

1 The involvement of cellular immunity in controlling the infection is strongly suggested by the intense granulomatous infiltration observed in the periparasitic area of lesions in experimentally infected mice (Bresson-Hadni et al., 1990; Emery et al., 1996; Vuitton et al., 1989). Immunodeficient athymic nude (Playford \& Kamiya, 1992) and SCID mice (Playford et al., 1992) as well as HIV-co-infected patients (Sailer et al., 1997; Zingg et al., 2004) exhibited high susceptibility to infection and disease, thus suggesting that the host cell mediated immune response plays an important role in suppressing the larval growth. E. multilocularis appears to induce skewed Th2-responses (Emery et al., 1996). Based on in vitro and in vivo studies, Th2 dominated immunity was associated with increased susceptibility to disease, while Th1 cell activation through IL-12 (Emery et al., 1996), IFN (Liance et al., 1998; Jenne et al., 1998), TNFa (Amiot et al., 1999) and IFN (Godot et al., 2003) was suggested to induce protective immunity in AE (Emery et al., 1998; Vuitton, 2003). Nevertheless, effective suppression of larval growth by means of an immunological attack is

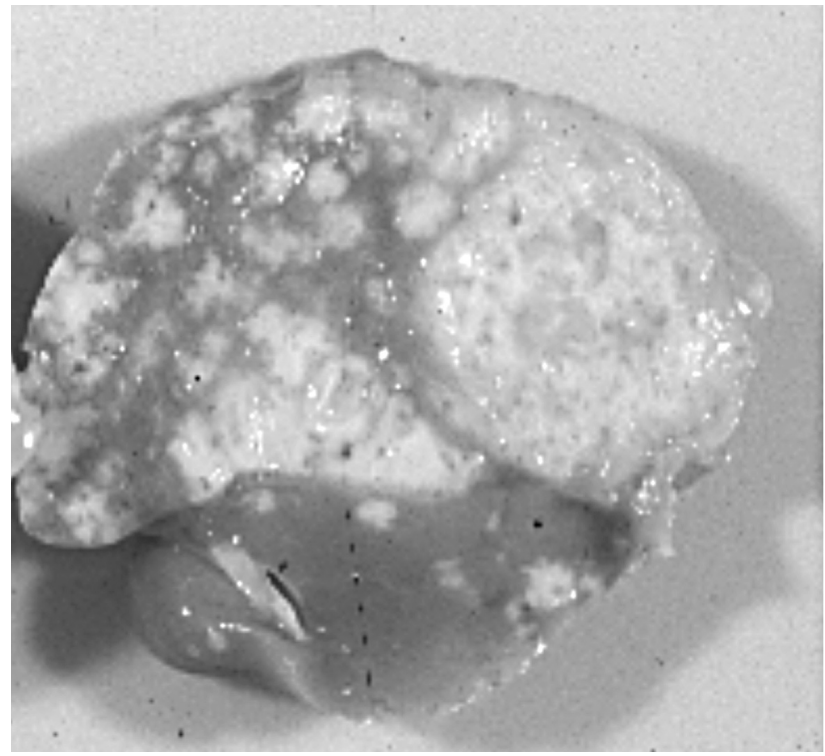

Fig. 1. - Macroscopic cross-section through a primate liver heavly affected by alveolar echinococcosis (metacestode of Echinococcus multilocularis).

hampered by the fact, that the parasite synthesizes a carbohydrate-rich laminated layer in order to be protected from host effector mechanisms (Gottstein \& Hemphill, 1997). Another interesting feature observed in chronic $\mathrm{AE}$ is a marked depression of the cell-mediated immune response (Baron \& Tanner, 1976; Devouge \& Ali-Khan, 1983; Kizaki et al., 1991; 1993). These general characteristics of E. multilocularis, including the seemingly tumor like growth, its ability to modulate host immune responses, and the fact that in vitro culture is an established technique, renders this parasite a very attractive model to study the host-parasite interplay in view to reveal potentially novel modes of therapy (Vuitton, 2003). The larval infection with E. multilocularis begins with the intrahepatic postoncospheral development of a metacestode. In certain cases, an appropriate host immune response may inhibit parasite proliferation. Several lines of evidence obtained in vivo and in vitro indicate the important bio-protective role of the LL (Gottstein et al., 2002). For instance, the LL has been proposed to protect the GL from nitric oxide produced by periparasitic macrophages and dendritic cells, and also to prevent immune recognition by surrounding T cells. On the other hand, the high periparasitic NO production by peritoneal exudate cells contributes to periparasitic immunosuppression (Dai et al., 1999; Andrade et al., 2004), explaining why iNOS deficient mice exhibit a significantly lower susceptibility towards experimental infection (Dai et al., 2003). The intense periparasitic granulomatous infiltration indicates an intense host-parasite interaction, and the involvement of cellular immunity in control of the metacestode growth kinetics is strongly suggested by 
experiments carried out in T cell deficient mouse strains (Dai et al., 2004). Carbohydrate components of the LL, such as Em2(G11) and Em492, as well as other parasite metabolites yield immunomodulatory effects that allow the parasite to survive in the host. I.e., the IgG response to the $\mathrm{Em} 2(\mathrm{G} 11)$-antigen takes place independently of alpha-beta+ $\mathrm{CD}^{+}{ }^{+} \mathrm{T}$ cells, and in the absence of interactions between CD40 and CD40 ligand (Dai et al., 2001). Such parasite molecules also interfere with antigen presentation and cell activation, leading to a mixed Th1/Th2-type response at the later stage of infection. Furthermore, Em492 (Walker et al., 2004) as a purified parasite metabolite suppresses ConA and antigen-stimulated splenocyte proliferation. Infected mouse macrophages (AE-M $\varnothing$ ) as APCs exhibited a reduced ability to present a conventional antigen (chicken ovalbumin, C-Ova) to specific responder lymph node T cells when compared to normal MØ (Mejri \& Gottstein, 2006). As AE-M $\varnothing$ fully maintained their capacity to appropriately process antigens, a failure in $\mathrm{T}$ cell receptor occupancy by antigen-Ia complex or/and altered co-stimulatory signals can be excluded. Studying the status of accessory molecules implicated in T cell stimulation by M $\varnothing$, it could be shown that B7-1 (CD80) and B7-2 (CD86) remained unchanged, whereas CD40 was down-regulated and CD54 (= ICAM-1) slightly upregulated. FACS analysis of peritoneal cells revealed a decrease in the percentage of $\mathrm{CD}^{+}$and $\mathrm{CD}^{+} \mathrm{T}$ cells in AE-infected mice. Taken together, the obstructed presenting-activity of AE-M $\varnothing$ appeared to trigger an unresponsiveness of $\mathrm{T}$ cells leading to the suppression of their clonal expansion during the chronic phase of $\mathrm{AE}$ infection (Mejri \& Gottstein, 2006).

\section{THE HUMAN IMMUNE RESPONSE IN E. MULTILOCULARIS INFECTION}

$\mathrm{R}$ elatively recent findings of naturally "aborted" calcified liver lesions in patients from various endemic areas (Godot et al., 2000; Gottstein et al., 2001) have indicated that not all infected human individuals allow the development of E. multilocularis metacestode. Clinical research on such "resistant" cases, but conversely also in AE patients with immunosuppression has disclosed some aspects of the survival strategy of E. multilocularis in human hosts (Vuitton, 2003). Immunosuppressive status such as in liver transplantation (Bresson-Hadni et al., 2003) or by AIDS (Sailer et al., 1997; Zingg et al., 2004), especially when suppressing cellular/Thl-related immunity, increases disease severity (Harraga et al., 1999; Manfras et al., 2004). Most studies so far have stressed a role for $\mathrm{CD}^{+} \mathrm{T}$ cells and for Interleukin-10 in the development disease susceptibility (Vuitton et al., 1989). A spontaneous secretion of IL-10 by the PBMC seems to be the immunological hallmark of patients with progressive forms of AE. IL10-induced inhibition of effector macrophages but also of antigen-presenting dendritic cells may be operating to protect the parasitic growth and survival (Vuitton et al., 2003). Susceptibility to infection in humans associates with predominantly TH2-related immunity (Wellinghausen et al., 1999), including IL-10 (Godot et al., 1997; 2000), IL-4 (Kilwinski et al., 1999), IL-5 (Sturm et al., 1995) production, especially during chronic stage of infection.

\section{BIOLOGICAL FEATURES OF TRICHINELLA SPIRALIS}

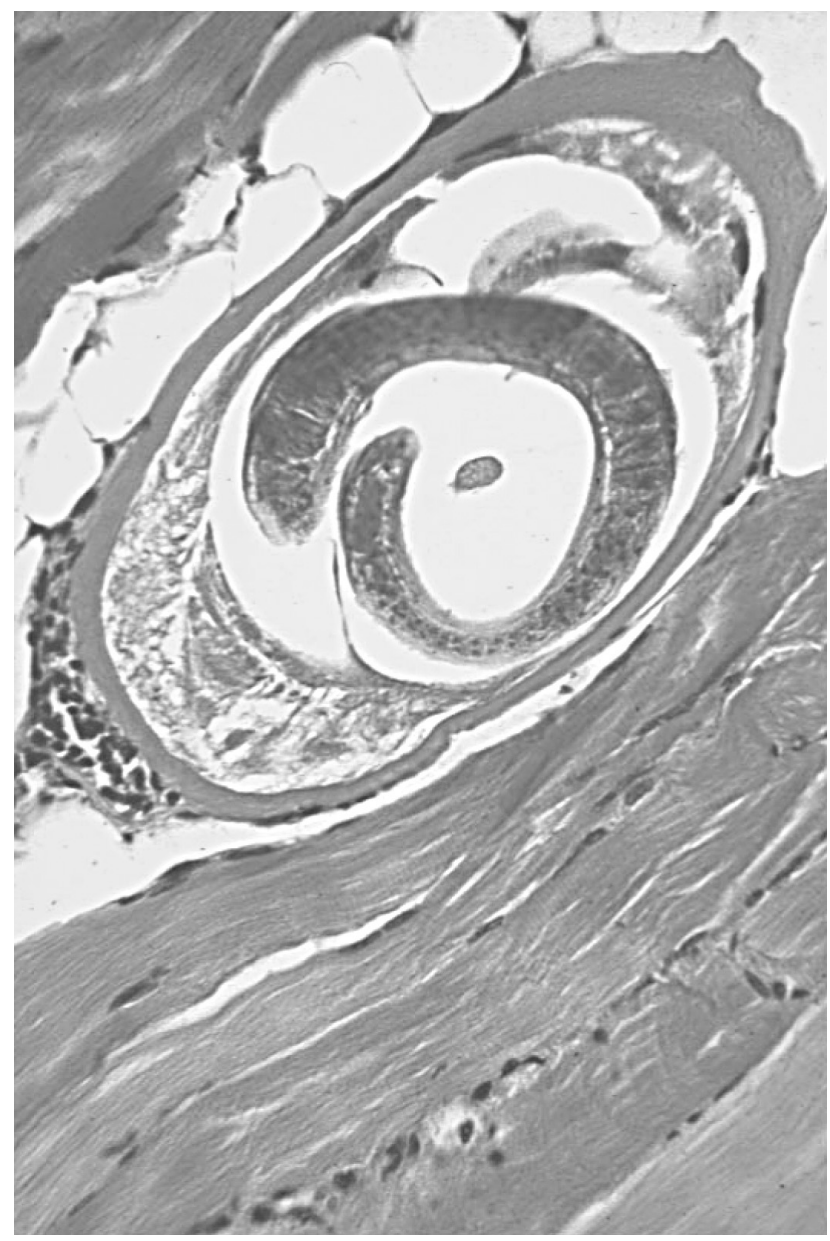

Fig. 2. - Histological section through muscle tissue containing an encapsulated muscle stage larva of Trichinella spiralis. 
devoid of muscle-specific proteins, which remains multinucleated and whose predestinated functionis to support the growth, the maturation and the maintenance of the parasite larva throughout the whole host life (Despommier, 1998). The transformation of the original host muscle cell into a nurse cell takes approximately 15-20 days. The fully maturated and larve reside in a cyst encapsulated in an adventitious ellipsoidal sheath with blunt ends resulting from cellular reactions around the tightly coiled larva (Fig. 2). Nourishing of the larva might be mainly via amino acids and carnohydrate metabolites so that it can remain alive for many years. The phenomenon of nurse cell transformation has been tackled experimentally, in view of determining how the parasite modulates these events. Thus, the addition of excretory/secretory (E/S) products from newborn larvae or muscle larvae into a culture of myocytes was shown to elicit morphological changes in myotubes, such as the formation of nodular structures that contain numerous cavities, probably due to enzymatic digestion by parasitic proteases (Leung \& Ko, 1997). Protease activities have been identified in (E/S) products and crude extracts of T. spiralis (Criado-Fornelio et al., 1992; de Armas-Serra et al., 1995; Todorova et al., 1995; Todorova \& Stoyanov, 2000; Todorova \& Stoyanov, 2000; Ros-Moreno et al., 2000). Serine protease (Romaris et al., 2002; Nagano et al., 2003) and a metalloproteinase (Lun et al., 2003) were cloned and identified from E/S products of T. spiralis muscle larvae (reviewed in Dzik, 2006; Trap et al., 2006).

\section{TRICHINELLA INFECTION IN THE HOST}

W hile there is ample information available on the dissection of the immune response against intestinal Trichinella infection, the respective information is much more scarce for the muscle stage infection. Some key components historically tackled as being relevant to dictating the course of infection for muscle stage larvae of Trichinella spiralis include IgE, eosinophils and mast cells (Gurish et al., 2007; Watanabe et al., 2005). More recently, some groups have nicely addressed the cooperative interplay among IL10 (Beiting et al., 2004), TGF- $\beta$, Teff, and Treg that ensures parasite survival while protecting the host from inflammatory disease in murine trichinellosis (Beiting et al., 2007). Trichinellosis in humans is acquired by consuming the meat of host animals that contain viable encysted larvae of Trichinella spp. The muscle phase of the disease begins about one week after infection when the larvae from the intestine disseminate hematogenously and begin to encyst in striated muscles. Patients may subsequently suffer from subconjunctival, retinal and subungual splinter hemorrhages, and periorbital and facial oedema. In line with the larvae maturating in its nurse cell, thew patient develops myalgia, fatique, elevated muscle enzymes and eosinophilia (Capo \& Despommier, 1996). Eosinophilia is present in more than $90 \%$ of the patients with symptomatic trichinellosis and abates only slowly over many months. Pathogenetically, chronic inflammatory cells may surround the parasitized nurse cell. Vasculitis will cause periorbital oedema as listed above, and neurological manifestations as well as myocarditis are major sequelae during trichinellosis of humans. Conversely to wild-life animal hosts, in man a calcification of the cyst takes place after six months and may lead to death of the larva.

\section{BIOLOGICAL FEATURES OF TOXOCARA CANIS}

$\mathrm{T}$ loxocariasis is a result of infection with embryonated eggs from Toxocara canis or Toxocara cati. After peroral ingestion of embryonated eggs by an appropriate intermediate host including humans and mice, the L3 (Brunaska et al., 1995) will hatch in the small intestine, migrate to the intestinal wall and subsequently circulate via the blood stream. After being blocked up in capillaries, larvae actively get through vascular wall and migrate into the host tissues (Fig. 3). There, host cells gain contact with the larvae, and particularly with their epicuticule, binding and releasing large amount of Toxocara Excretory/Secretory (TES) antigens. These antigens, first isolated by de Savigny (1975), are produced by oesophageal glands and the secretory apparatus of the larvae (Page et al., 1992a, b). The metabolites are heavily glycosylated and they entirely cover the surface of the larvae, thus representing the unique site of physical contact between parasite and host (Page et al., 1992b). The results of this contact is a marked release of tumour necrosis factor alpha (TNF- $\alpha$ ) and interleukine 8 (IL-8) which can specifically bind to receptors of endothelium cell of capillaries. Stimulation of these cells results in an increase of expression of leukocyte adhesion molecule on their surface. Neutrophils are the first cells to contribute to the inflammatory infiltrate into the lung of mice infected with T. canis (Kayes, 2006). This early inflammatory infiltrate represents the innate response, and is subsequently followed, after less than a week, by the binding of eosinophils to endothelium cells receptors VCAM-1 and ELAM-1 (vascular cell adhesion molecule 1 and endothelial leucocyte adhesion molecule 1, respectively). A Th2 response is considered as being responsible for the hypereosinophilia and the IgE hyperglobulinemia. However, eosinophils, even with the cooperation of antibodies, are unable to kill infectious larvae. This is partially due to the fact that larvae permanently slough 


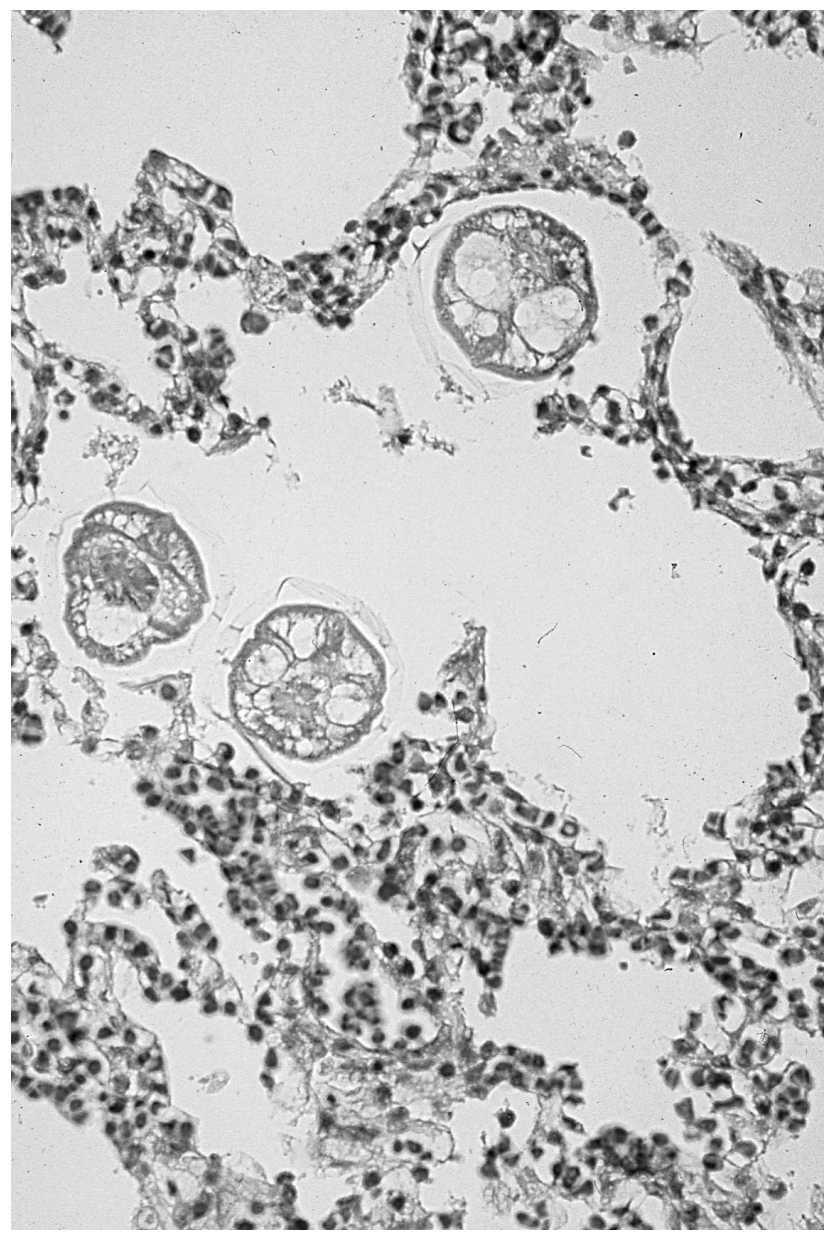

Fig. 3. - Histological presentation (HE-stain) of lung tissue containing three cross-sections of larvae from Toxocara canis, and many inflammatory cell infiltrates.

off their epicuticule leading to an elimination of antibodies and cells which are attacking the larva (Badley et al., 1987; Parson et al., 1993; Jones et al., 1994; Dent et al., 1997, 1999; Ovington \& Behm, 1997; Takamoto et al., 1997). The migration of the larvae may also play a role by helping the parasite to escape encapsulation into granuloma. Finally, the role of eosinophils in the resistance to Toxocara infection appears relatively minor (Dent et al., 1999; Meeusen \& Balic, 2000) and Antibody-Dependent Cell-mediated Cytotoxicity (ADCC) directed against the incoming larvae in non-sensitized hosts is hardly protective. Other cells may play a role, such as the macrophages termed alternatively macrophages (Stein et al., 1992). These cells express F4/80, a macrophage surface marker molecule, and Nair et al. (2003) showed that $10 \%$ of the mRNAs isolated from F4/80-positive cells encoded the YM-1 protein, a member of the kitinase 18 family. These chitinases have been reported in mice and in human and have been implicated in helminth infection and in asthma and allergy. Finally, immune response against T. canis in human and mouse is characterized by high and persisting eosinophilia, and production of cytokines typical for a Th-2 type immune response (IL-4, IL-5, IL-10) and increased IgE antibodies levels (Kayes, 1997) unable to kill the larvae. Consequently, larvae can remain for years in the muscle and brain and thus can cause longterm chronic infection and disease.

\section{TOXOCARA INFECTION IN THE HUMAN HOST}

\begin{abstract}
Tn humans, Toxocara typically causes two severe syndromes called either visceral larva migrans (VLM) Lor ocular larva migrans (OLM). OLM was first described by Wilder (1950) who reported 24 cases in children suspected of having retinoblastoma. Migration of T. canis infectious stage larvae to the eye causes loss of vision and the presence of only one larva in the ocular cavity can cause irreversible blindness. VLM was described two years later, by Beaver et al. (1952) in three children suffering from hepatomegaly and hypereosinophilia. VLM typically affects children with a history of geophagia and exposure to puppies at home. In VLM cases, hepatic and pulmonary larval migration induces clinical symptoms such as abdominal pain, decreased appetite, restlessness, fever, coughing, wheezing, asthma and hepatomegaly. Cutaneous manifestations includes transient rash, urticaria and hypodermic nodules. The main laboratory findings are marked eosinophilia, leukocytosis, hypergammaglobulinemia, anemia and hypoalbuminemia (Markell et al., 1999). Less severe forms of toxocariasis occur in industrialized countries and are called common toxocariasis and covert toxocariasis. Common toxocariasis was first described by Glickman et al. (1987) in French adults presenting with weakness, breathing difficulties, abdominal pain, and also skin symptoms such as pruritus and rash associated with biological signs of allergic manifestation (hypereosinophilia and increased total serum IgE). The spectrum of covert toxocariasis was identified the same year in Irish children (Taylor et al., 1987). It includes various symptoms such as fever, anorexia, headache, abdominal pain, nausea, coughing, wheezing and behaviour disorders.
\end{abstract}

\section{CONCLUSIONS}

Tr nnate and acquired immunity plays a central role in recognizing and controlling the spread and impact on the host of infectious organisms. In the case of helminthic infections this task is significantly complicated by the fact that many eukaryotic parasites have evolved sophisticated mechansims for evading the immune 
response. Consequently, many diseases caused by helminths are chronic in nature and result in prolonged and excessive immune responsiveness which in itself can be deleterious. The study of immune responses to helminths has been important not only because of the potential for improving human and animal health through immunological means, but also because the extreme nature of many parasite-induced responses allow to get insights into the functioning of the immune system and aberrant immunopathological diseases itself. Alveolar echinococcosis, trichinellosis and toxocarosis are three helminthic diseases that still pre-occupy clinicians in industrialized countries of central Europe, and thus allow not only to carry out basic laboratory research studies in animal models, but also to perform clinical studies on patients in order to improve public health and treatment strategies for the handling and control of respective problems.

\section{REFERENCES}

Amiot F., Vuong P., Defontaines M., Pater C., Dautry F. \& UANCE M. Secondary alveolar echinococcosis in Iymphotoxinalpha and tumour necrosis factor-alpha deficient mice: exacerbation of Echinococcus multilocularis larval growth is associated with cellular changes in the periparasitic granuloma. Parasite Immunol., 1999, 21, 475-483.

Andrade M.A., Siles-Lucas M., Espinoza E., Pérez Arellano J.L., GotTSTEIN B. \& Muro A. Echinococcus multilocularis laminated-layer components and the E14t 14-3-3 recombinant protein decrease activated rat macrophages NO production in vitro. Nitric Oxide, 2004, 10, 150-155.

Badley J.E., Grieve R.B., Rockey J.H. \& Glickman L.T. Immunemediated adherence of eosinophils to Toxocara canis infective larvae: the role of excretory-secretory antigens. Parasite Immunol., 1987, 9, 133-143.

BARON R.W. \& TANNER C.E. The effect of immunosuppression on secondary Echinococcus multilocularis infections in mice. Int. J. Parasitol., 1976, 6, 37-42.

Beaver P.C., Snyder C.H. \& Carrera G.M. Chronic eosinophilia due to visceral larva migrans. Pediatrics, 1952, 9, 7-19.

Beiting D.P., Bliss S.K., Schlafer D.H., Roberts V.L. \& Appleton J.A. Interleukin-10 limits local and body cavity inflammation during infection with muscle-stage Trichinella spiralis. Inf. Immunity, 2004, 72, 3129-3137.

Beiting D.P., Gagliardo L.F., Hesse M., Bliss S.K., Meskill D. \& APPLETON J.A. Coordinated control of immunity to muscle stage Trichinella spiralis by IL-10, regulatory T cells, and TGF- $\beta$. J. Immunol., 2007, 178, 1039-1047.

Bresson-Hadni S., Koch S., Miguet J.P., Gillet M., Mantion G.A., Heyd B. \& VuitTon D.A. European group of clinicians. Indications and results of liver transplantation for Echinococcus alveolar infection: an overview. Langenbecks Arch. Surg., 2003, 388,231-238.

Bresson-Hadni S., Liance M., Meyer J.P., Houin R., Bresson J. \& VuitTon D. Cellular immunity in experimental Echino- coccus multilocularis infection. II. Sequential and comparative phenotypic study of the periparasitic mononuclear cells in resistant and sensitive mice. Clin. Exp. Immunol., 1990, 82, 378-383.

Brunaska M., Dubinsky P. \& Reiterova K. Toxocara canis: ultrastructural aspects of larval moulting in the maturing eggs. Int. J. Parasitol., 1995, 25, 683-690.

CAPO V. \& Despommier D.D. Clinical aspects of infection with Trichinella spp. Clin. Microbiol. Rev., 1996, 9, 47-54.

Criado-Fornelio A., De Armas-Serra C., Gimenez-Pardo C., Casado-Escribano A., Jimenez-Gonzalez A. \& RodriguezCAabeiro F. Proteolytic enzymes from Trichinella spiralis larvae. Vet. Parasitol., 1992, 45, 133-140.

Dai W.J. \& GotTstein B. Nitric oxide-mediated immunosuppression following murine Echinococcus multilocularisinfection. Immunology, 1999, 97, 107-116.

Dai W.J., Hemphill A., Waldvogel A., Ingold K., Deplazes P., Mossmann H. et al. Major carbohydrate antigen of Echinococcus multilocularis induces an immunoglobulin $\mathrm{G}$ response independent of alpha beta $\left(^{+}\right) \operatorname{CD} 4\left(^{+}\right) \mathrm{T}$ cells. Inf. Immun., 2001, 69, 6074-6083.

Dai W.J., Waldvogel A., Jungi T., Stettler M. \& Gottstein B. Inducible nitric oxide synthase-deficiency in mice increases resistance to chronic infection with Echinococcus multilocularis. Immunology, 2003, 10, 238-244.

Dai W.J., Waldvogel A., Siles-Lucas M. \& GotTstein B. Echinococcus multilocularis proliferation in mice and respective parasite 14-3-3 gene expression is mainly controlled by an alphabeta CD4 T-cell-mediated immune response. Immunology, 2004, 112, 481-488.

De Armas-Serra C., Gimenes-Pardo C., Jimenez-Gonzalez A., Bernadina W.E. \& Rodriguez-CaAbeiro F. Purification and preliminary characterization of a protease from the excretion-secretion products of Trichinella spiralis muscle-stage larvae. Vet. Parasitol., 1995, 59, 157-168

De Savigny D.H. In vitro maintenance of Toxocara canis larvae and a simple method for the production of Toxocara ES antigen for use in serodiagnostic tests for visceral larva migrans. J. Parasitol., 1975, 61, 781-782.

Dent L.A., Daly C.M., Mayrhofer G., Zimmerman T., Hallett A., Bignold L.P., Creaney J. \& Parsons J.C. Interleukin-5 transgenic mice show enhanced resistance to primary infections with Nippostrongylus brasiliensis but not primary infections with Toxocara canis. Infect. Immun., 1999, 67, 989-993.

Dent l.A., Daly C., Geddes A., Cormie J., Finlay D.A., Bignold L., Hagan P., Parkhouse R.M., Garate T., Parsons J. \& MayRHOFER G. Immune responses of IL-5 transgenic mice to parasites and aeroallergens. Mem. Inst. Oswaldo Cruz, 1997, 92 (Suppl. 2), 45-54.

Despommier D.D. How does Trichinella spiralis make itself at home? Parasitol. Today, 1998, 14, 318-323.

Devouge M. \& Ali-Khan Z. Intraperitoneal murine alveolar hydatidosis: relationship between the size of the larval cyst mass, immigrant inflammatory cells, splenomegaly and thymus involution. Tropenmed. Parasitol., 1983, 34, 15-20.

DzIK J.M. Molecules released by helminth parasites involved in host colonization. Acta Biochimica Polonica, 2006, 53, 33-64. 
Emery I., Leclerc C., Sengphommachanh K., Vuitton D.A. \& LIANCE M. In vivo treatment with recombinant IL-12 protects C57BL/6J mice against secondary alveolar echinococcosis. Parasite Immunol., 1998, 20, 81-91.

Emery I., Liance M., Deriaud E., Vuitton D., Houin R. \& LECLERC C. Characterization of T-cell immune responses of Echinococcus multilocularis infected C57BL/6 mice. Parasite Immunol., 1996, 18, 463-472.

Glickman L.T., Magnaval J.F., Domanski L.M., Shofer F.S., LAURIA S.S., GotTsteIn B. \& BROChIER B. Visceral larva migrans in French adults: a new disease syndrome? Am. J. Epidemiol., 1987, 125, 1019-1034.

Godot V., Harraga S., Deschaseaux M., Bresson-Hadni S., GotTstein B., Emilie D. \& VuitTon D.A. Increased basal production of interleukin-10 by peripheral blood mononuclear cells in human alveolar echinococcosis. Eur. Cytokine Netw., 1997, 8, 401-408.

Godot V., Harraga S., Podoprigora G., Liance M., BardonNET K. \& VuITTON D.A. IFN alpha-2a protects mice against a helminth infection of the liver and modulates immune responses. Gastroenterology, 2003, 124, 1441-1450.

Godot V., Harraga S., Beurton I., Deschaseaux M., SarciRON E., GotTstein B. \& VuitTon D.A. Resistance/susceptibility to Echinococcus multilocularis infection and cytokine profile in humans. I - Comparison of patients with progressive and abortive lesions. Clin. Exp. Immunol., 2000, 121, 484-490.

Gottstein B., Dai W.J., Walker M., Stettler M., Muller N. \& Hemphill A. An intact laminated layer is important for the establishment of secondary Echinococcus multilocularis infection. Parasitol. Res., 2002, 88, 822-828.

Gottstein B., Saucy F., Deplazes P., Reichen J., Demierre G., Zürcher C., Busato A. \& Pugin P. Is a high prevalence of Echinococcus multilocularis in wild and domestic animals associated with increased disease incidence in humans? Emerging Infectious Diseases, 2001, 7, 408-412.

GotTstein B. \& Hemphill A. Immunopathology in echinococcosis, in: Immunopathogenetic aspects of disease induced by helminth parasites. Freedman D.O (ed.), S. Karger AG, Basel, 1997, 177-208.

Gurish M.F., Humbles A., TaO H., Finkelstein S., Boyce J.A., Gerard C., Friend D.S. \& Austen K.F. CCR3 is required for tissue eosinophilia and and larval cytotoxicity after infection with Trichinella spiralis. J. Immunol., 2007, 168, 57305736.

Harraga S., Godot V., Bresson-Hadni S., Pater C., Beurton I., Bartholomot B. \& Vutton D.A. Clinical efficacy of and switch from $\mathrm{T}$ helper 2 to $\mathrm{T}$ helper 1 cytokine profile after interferon alpha2a monotherapy for human echinococcosis. Clin. Infect. Dis., 1999, 29, 205-206.

Jenne L., Kilwinski J., Aadloff P., Flick W. \& Kern P. Clinical efficacy of and immunologic alterations caused by interferon gamma therapy for alveolar echinococcosis. Clin. Infect. Dis., 1998, 26, 492-494.

Jones R.E., Finkelman F.D., Hester R.B. \& Kayes S.G. Toxocara canis: failure to find IgE receptors ( $\mathrm{FC}_{\mathrm{C}}$ epsilon $\mathrm{R}$ ) on eosinophils from infected mice suggests that murine eosinophils do not kill helminth larvae by an IgE-dependent mechanism. Exp. Parasitol., 1994, 78, 64-75.
KAYES S.G. Inflammatory and immunological responses to Toxocara canis, in: Toxocara the enigmatic parasite. Holland C.V. \& Smith H.V. (eds), Cabi Publishing, Cambridge MA USA, 2006.

KAYES S.G. Human toxocariasis and the visceral larva migrans syndrome: correlative immunopathology. Chem. Immunol., 1997, 66, 99-124.

Kilwinski J., Jenne L., Jellen-Aitter A., Radloff P., Flick W. \& KERN P. T lymphocyte cytokine profile at a single cell level in alveolar echinococcosis. Cytokine, 1999, 11, 373-381.

Kizaki T., Ishige M., Bingyan W., Day N.K., Good R.A. \& OnOE K. Generation of $\mathrm{CD}^{+}$suppressor T cells by proto scoleces of Echinococcus multilocularis in vitro. Immunology, 1993, 79, 412-417.

Kizaki T., Kobayashi S., Ogasawara K., Day N.K., Good R.A. \& ONOE K. Immune suppression induced by protoscoleces of Echinococcus multilocularis in mice. Evidence for the presence of CD8dull suppressor cells in spleens of mice intraperitoneally infected with E. multilocularis. J. Immunol., 1991, 147, 1659-1666.

LEUNG R.K. \& Ko R.C. In vitro effects of Trichinella spiralis on muscle cells. J. Helminthol., 1997, 71, 113-118.

Liance M., Aicard-Blum S., Emery I., Houin A. \& VuitTon D.A. Echinococcus multilocularis infection in mice: in vivo treatment with a low dose of IFN-gamma decreases metacestode growth and liver fibrogenesis. Parasite, 1998, 5, 231-237.

Lun M., MAK C.H. \& Ko R.C. Characterization and cloning of metallo-proteinase in the excretory/secretory products of the infective-stage larva of Trichinella spiralis. Parasitol. Res., 2003, 90, 27-37.

Nagano I., Wu Z., Nakada T., Boonmars T. \& TaKahashi Y. Molecular cloning and characterization of a serine proteinase gene of Trichinella spiralis. J. Parasitol., 2003, 89, 92-98.

Manfras B.J., Reuter S., Wendland T., Boehm B.O. \& Kern P. Impeded Th1 CD4 memory $\mathrm{T}$ cell generation in chronicpersisting liver infection with Echinococcus multilocularis. Int. Immunol., 2004, 16, 43-50.

Markell E.K., John D.T. \& Krotoski W.A. Sings and symptoms of parasitic disease, in: Markell and Voge's medical parasitology. Markell E.K., John D.T., Krotoski W.A. (eds), Philadelphia, WB Saunders, 1999, 465-478.

MejRI N. \& GotTsteIn B. Intraperitoneal Echinococcus multilocularis infection in C57BL/6 mice affects CD40 and B7 co-stimulator expression on peritoneal macrophages and impairs peritoneal T cell activation. Parasite Immunol., 2006, 28, 373-385.

Meeusen E.N. \& Balic A. Do eosinophils have a role in the killing of helminth parasites? Parasitol. Today, 2000, 16, 95-101.

Nair M.G., Cochrane D.W. \& Allen J.E. Macrophages in chronic type 2 inflammation have a novel phenotype characterized by the abundant expression of Ym1 and Fizz1 that can be partly replicated in vitro. Immunol. Lett., 2003, 85, 173-180.

Ovington K.S. \& Behm C.A. The enigmatic eosinophil: investigation of the biological role of eosinophils in parasitic helminth infection. Mem. Inst. Oswaldo Cruz, 1997, 92 (Suppl. 2), 93-104. 
Page A.P., Hamilton A.J. \& Maizels R.M. Toxocara canis: monoclonal antibodies to carbohydrate epitopes of secreted (TES) antigens localize to different secretion-related structures in infective larvae. Exp. Parasitol., 1992, 75, 56-71.

Page A.P., Rudin W., Fluri E., Blaxter M.L. \& Maizels R.M. Toxocara canis: a labile antigenic surface coat overlying the epicuticle of infective larvae. Exp. Parasitol., 1992, 75, 72-86.

Parsons J.C., Coffman R.L. \& Grieve R.B. Antibody to interleukin 5 prevents blood and tissue eosinophilia but not liver trapping in murine larval toxocariasis. Parasite Immunol., 1993, 15, 501-508.

Playford M.C. \& KamiYa M. Immune respoflse to Echinococcus multilocularis infection in the mouse model. Jpn. J. Vet. Res., 1992, 40, 113-130.

Playford M.C., OOI H.K., OKu Y. \& KamiYa M. Secondary Echinococcus multilocularis infection in severe combined immunodeficient (scid) mice: biphasic growth of the larval cyst mass. Int. J. Parasitol., 1992, 22, 975-829.

Romaris F., North S.J., Gagliardo L.F., Butcher B.A., GHOSh K., Beiting D.P., Panico M., Arasu P., Dell A., Morris H.R. \& Appleton J.A. A putative serine protease among the excretory-secretory glycoproteins of L1 Trichinella spiralis. Mol. Biochem. Parasitol., 2002, 122, 149-160.

Ros-Moreno R.M., Vázquez-López C., Giménez-Pardo C., DE ARMasSERra C. \& Rodríguez-CAabeiro F. A study of proteases throughout the life cycle of Trichinella spiralis. Folia Parasitol. (Praha), 2000, 47, 49-54.

Sailer M., Soelder B., Allerberger F., Zaknun D., Feichtinger H. \& GotTstein B. Alveolar echinococcosis of the liver in a six-year-old girl with acquired immunodeficiency syndrome. J. Pediatr., 1997, 130, 320-323.

Sturm D., Menzel J., Gottstein B. \& Kern P. Interleukin-5 is the predominant cytokine produced by peripheral bloodmononuclear cens in alveolar echinococcosis. Infect. Immun., 1995, 63, 1688-1697.

Stein M., Keshav S., Harris N. \& Gordon S. Interleukin-4 potently enhances murine macrophage mannose receptor activity: a marker of alternative immunologic macrophage activation. J. Exp. Med., 1992, 17, 287-292.

Taylor M.R., Keane C.T., O'Connor P., Girdwood R.W.A. \& SMITH H. Clinical features of covert toxocariasis. Scand.J. Infect. Dis., 1987, 19, 693-696.

Takamoto M., Ovington K.S., Behm C.A., Sugane K., Young I.G. \& MAtThaEi K.I. Eosinophilia, parasite burden and lung damage in Toxocara canis infection in $\mathrm{C} 57 \mathrm{Bl} / 6$ mice genetically deficient in IL-5. Immunology, 1997, 90, 511-517.

TODOROVA V.K. \& STOYANOv D.I. Partial characterization of serine proteinases secreted by adult Trichinella spiralis. Parasitol. Res., 2000, 86, 684-687.

Todorova V.K., Knox D.P. \& Kennedy M.W. Proteinases in the excretory/secretory products (ES) of adult Trichinella spiralis. Parasitology, 1995, 111, 201-208.

Trap C., Fu B., Le Guerhier F., Liu M., Le Rhun D., Romand T., Perret C., Blaga R. \& Boireau P. Cloning and analysis of a cDNA encoding a putative serine protease comprising two trypsin-like domains of Trichinella spiralis. Parasitol. Res., 2006, 98, 288-294.
Vuttton D.A., Bresson-Hadni S., Laroche L., Kaiserlian D., Guerret-Stocker S., Bresson J.L. \& Gillet M. Cellular immune response in Echinococcus multilocularis infection in humans. II. Natural killer cell activity and cell subpopulations in the blood and in the periparasitic granuloma of patients with alveolar echinococcosis. Clin. Exp. Immunol., 1989, 78, 67-74.

VuitTon D.A. The ambiguous role of immunity in echinococcosis: protection of the host or of the parasite? Acta Trop., 2003, 85, 119-132.

Walker M., Baz A., Dematteis S., Stettler M., Gottstein B., SCHALLER J. et al. Isolation and characterization of a secretory fraction of Echinococcus multilocularis metacestode potentially involved in modulating the host-parasite interface. Infect. Immun., 2004, 72, 527-536.

Watanabe N., Bruschi F. \& Korenaga M. IgE: a question of protective immunity in Trichinella spiralis infection. Trends Parasitol., 2005, 21, 175-178.

Wellinghausen N., Gebert P. \& Kern P. Interleukin (IL)-4, IL10 and IL-12 profile in serum of patients with alveolar echinococcosis. Acta Trop., 1999, 73, 165-174.

Wilder H.C. Nematode endophthalmitis. Trans. Am. Acad. Ophthalmol. Otolaryngol., 1950, 51, 99-109.

ZingG W., Renner-Schneiter E.C., Pauli-Magnus C., Renner E.L., VAN Overbeck J., Schläpfer E., Weber M., Weber R., Opravil M., GotTstein B., Speck R.F. \& THE Swiss HIV CoHort Study. Alveolar echinococcosis of the liver in an adult with human immunodeficiency virus type-1 infection. Infection, 2004, 32, 299-302. 